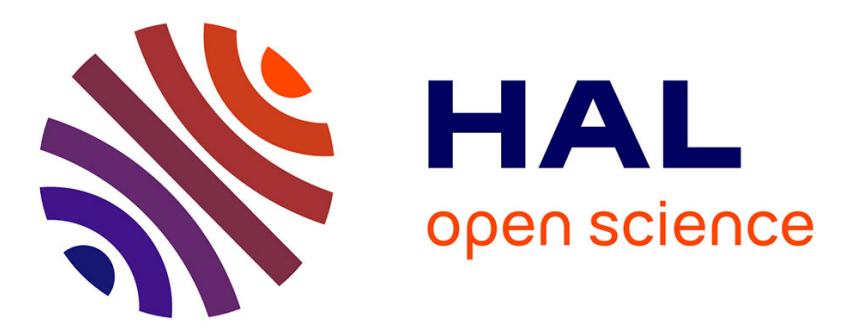

\title{
Logistic corridors modelled with agent-based approach and dynamic graphs
}

\author{
Thibaut Démare, Cyrille Bertelle, Antoine Dutot, Laurent Lévêque
}

\section{To cite this version:}

Thibaut Démare, Cyrille Bertelle, Antoine Dutot, Laurent Lévêque. Logistic corridors modelled with agent-based approach and dynamic graphs. 4th International Conference on Advanced Logistics and Transport (ICALT 2015), May 2015, Valenciennes, France. pp.199 - 204, 10.1109/ICAdLT.2015.7136619 . hal-01433143

\section{HAL Id: hal-01433143 \\ https://hal.science/hal-01433143}

Submitted on 12 Jan 2017

HAL is a multi-disciplinary open access archive for the deposit and dissemination of scientific research documents, whether they are published or not. The documents may come from teaching and research institutions in France or abroad, or from public or private research centers.
L'archive ouverte pluridisciplinaire HAL, est destinée au dépôt et à la diffusion de documents scientifiques de niveau recherche, publiés ou non, émanant des établissements d'enseignement et de recherche français ou étrangers, des laboratoires publics ou privés. 


\section{Logistic Corridors Modelled with Agent-based Approach and Dynamic Graphs}

\author{
Thibaut Démare \\ Cyrille Bertelle \\ and Antoine Dutot \\ Normandie Univ, ULH, LITIS, Le Havre F-76600, France \\ Email: thibaut.demare@univ-lehavre.fr
}

\author{
Laurent Lévêque \\ Normandie Univ, ULH, IDEES, Le Havre F-76600, France
}

\begin{abstract}
This work is about the modelling of a logistic corridor in order to understand how a logistic system is structured and organised. An agent-based approach and dynamic graphs are used to integrate spatial constraints and functional rules of such a complex system which can be studied with a multi-scale point of view. An implementation on a simulation platform provides first results on a corridor of the Northern European range: the Seine axis. It is shown that the model can answer to the problematic but provides also features of decision support of spatial planning.
\end{abstract}

Keywords-agent-based model, dynamic graph, logistic system, modelling, complex system, geographical information system

\section{INTRODUCTION}

The current paper presents the modelling of a logistic system. This need comes from the increase of competition between ports and their inner corridor. The economical stakes are so important that it becomes a priority to understand how a logistic system is structured and organised in order to highlight its advantages and lacks of performance.

The literature mostly study either the port logistics or the metropolitan ones but this work regroups both views thanks to the integration of a logistic interface. After explaining the context of this work in the first section, the paper describes the model. It integrates a multi-scale point of view thanks to a complex system approach. It is made of a multi-agent system and of dynamic graphs in order to translate the spatial constraints and the actors' behaviours of such a system. The final section studies the implementation of the model on a simulation platform which provides results about the Seine axis.

\section{CONTEXT}

A logistic corridor is an environment with spatial, economical and political constraints and on which goods are transported to reach urban areas. The size of these metropolis and the growth of their demands imply a huge traffic, itself source of financial attractiveness. Moreover, the global performance of the logistic corridors allow them to expand themselves in order to deliver further new urban areas. And it grows so much that today, more and more logistic corridors are in competition to deliver the same urban areas. For instance, it is the case of Paris' region whose the goods mainly come from La Havre and Antwerp.
The economical stakes are important in order to increase its market share. Concerning the Seine axis, the recent port reform, the creation of HAROPA $^{1}$ or also the number of scientific works and projects about this axis show the interest to improve the performance of the system. That is translated by a wish to understand the organisation, the advantages and issues of a logistic corridor. More precisely, the problematic here is to model the whole system, integrating the spatial constraints and the functional rules of its actors. And the section below describes these characteristics.

The actors of the logistics [3] are mostly represented by these ones:

- The importers and the exporters: in the interests of the final customers' demands, they initiate the flows of goods thanks to a contract between them.

- The freighters: the one who takes in charge of the goods during the transport (it depends on the contract).

- The freight forwarders: they organize the transportation of goods on behalf of the freighter.

- The transporters (shipowner, road transporter,...): they move the goods according to the requests of the freight forwarder (destination, preferred path, duration,...).

- The logistic providers: they operates goods on the hinterland within and between logistic buildings. They outsource the stock of a freighter [7], [9], [12]. The structured organisation of logistic buildings is called the supply chain. The logistic buildings answer to particular needs and are arranged by the logistic provider into networks in order to atomise or to massify the flows of goods as on figures 1 and 2 .

But this list is not exhaustive. These actors are numerous and heterogeneous. They are in interactions with each other due to their behaviours but also due to the constraints of the environment (such as spatial restriction from the network). They are auto-organised into communities such as the port community which can be seen as a strong cluster of actors sometimes collaborating, sometimes in competition. This multi-scale point of view with the local rules in one hand, and global communities in the other hand, is revealing of the

\footnotetext{
${ }^{1}$ HAROPA is an Economic Interest Group (EIG) grouping within the same structure the ports of Le Havre, Rouen and Paris in order to help to the collaboration.
} 
complexity of the studied system. This complexity also appears in the organisation of the network of the infrastructures.

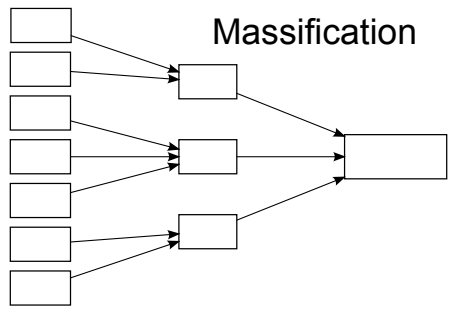

Fig. 1. Logistic buildings in a join network

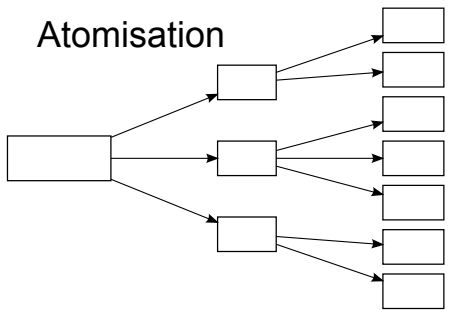

Fig. 2. Logistic buildings in a fork network

The goods move on a physical environment which appeared as a structured and organised multi-modal network, managed by actors (see figure 3). Each kind of network provides particular constraints (size of vehicles, speed,...). Some subnetworks allow to transport more goods at the same time (e.g. river network against road network), while some others allow to reach more destinations and more quickly (e.g. road network against rail network). Some of its infrastructures (e.g. terminals) have the function to move the goods from a kind of network (here maritime lines) to another one (e.g. road network). The other ones, the logistic buildings, exist in order to outsource the stocks of another building and/or to provide extra-logistics activities (e.g. container packing, quality control, cross-docking,...). The size of these buildings, the activities they provide, and how they are included in a supply chain define a particular structure where the buildings are organized into a hierarchy.

The important volumes between different nations or continents, such as between the Asia and the Europe, allow to massify the transportation of goods thanks to cargo ships in order to bring down the costs. But the maritime lines are often irregular and the port terminals need to process these sporadic but huge flows [8]. At the contrary, the actors of the urban areas manipulate regular flows. Moreover, because the urban areas are more or less spread over the territory of importation, the import flows of goods have to be atomised. This regularity and this atomisation is made possible thanks to a buffer interface between the port and the metropolises. This interface corresponds to this structured multi-modal network: its topology as a fork network (in the import side) allow the atomisation; and the outsourcing logistic buildings play the role of buffer in order to compensate the irregularity of the international transport.

Even if it is possible to observe local movements of goods at a micro level, overall patterns emerge at the macro level of the logistic corridor. The local constraints on the network lead the flows over the main paths and drive to congestion on these axis. It is again revealing of a complex system.

\section{MODELLING OF A LOGISTIC CORRIDOR}

The current section presents the modelling of a logistic corridor. The final goal of this modelling is to provide the keys to understand a logistic system and to provide an help to the decision making of spatial planning. Firstly, the model must have the ability to adapt itself to different kind of corridor: there is not the same spatial constraints everywhere; the actors can be subjected to different regulations... The actors can update easily their behaviours, and the infrastructures can be modified thanks to different input. Secondly, the model has to provide performance measures about traffic, congestion, time of transportation, costs (financial, or possibly environmental),...

It has been decided to choose an agent-based approach [4] coupled with dynamic graph [10], [13]. They are both known to be well-suited for complex system. They can report the spatial dimension of the system and they are configurable thanks to many parameters. The graph theory provides also a lot of measures in order to highlight traffic and congestion problems for instance.

The agent-based approach consists of representing the elements of a system as autonomous entities: the agents. Ferber [4] describes them as physical or virtual. They have their own capacity to act, to perceive their environment, and to interact with other agents or with the environment. The representation of this environment has a discrete or a continuous topology. These characteristics allow to model the spatial dimension of a logistic system but also can interpret the diversity of its elements (the actors and the infrastructures). The agent-based approaches have a real advantage over mathematical models such as dynamic systems thanks to this capacity to represent the heterogeneity and the spatiality of the system, and allow more precisions through parameters defined by users.

The graphs are mostly, in the literature [10], static mathematical structures representing elements (the nodes) in interaction (the edges) with each others. But the agent-based approach brings a dynamicity: agents do not interact at the same time with each others, and the flows over the territory evolve in time. But this dynamic is not integrated in the classical definition of a graph. Recent works [2], [5] define the dynamic of the topology as a sequence of graphs. Savin [13] also integrate the concept of dynamic over the data within nodes or edges. Thanks to this model, it is possible to represent a transportation network who can be subjected to accidents (deletion of an edge and therefore modification of the topology), or to congestions (modification of the amount on an edge).

Each agent represents an actor or an infrastructure of the system. Their autonomous decisions are taken from their own behaviour which depends on the kind of actor or infrastructure they model as on the figure 4. Their perceptions of the environment or their interactions with other agents can modify their behaviours and therefore their decisions. The person in charge of the shop or the factory manages his local stocks and choose a logistic provider to manage the outsourced stock. When the stocks fall too much, a person in charge of the importation (he can be part of the agent in charge of the shop or the factory) can order the delivery of goods from a provider. 


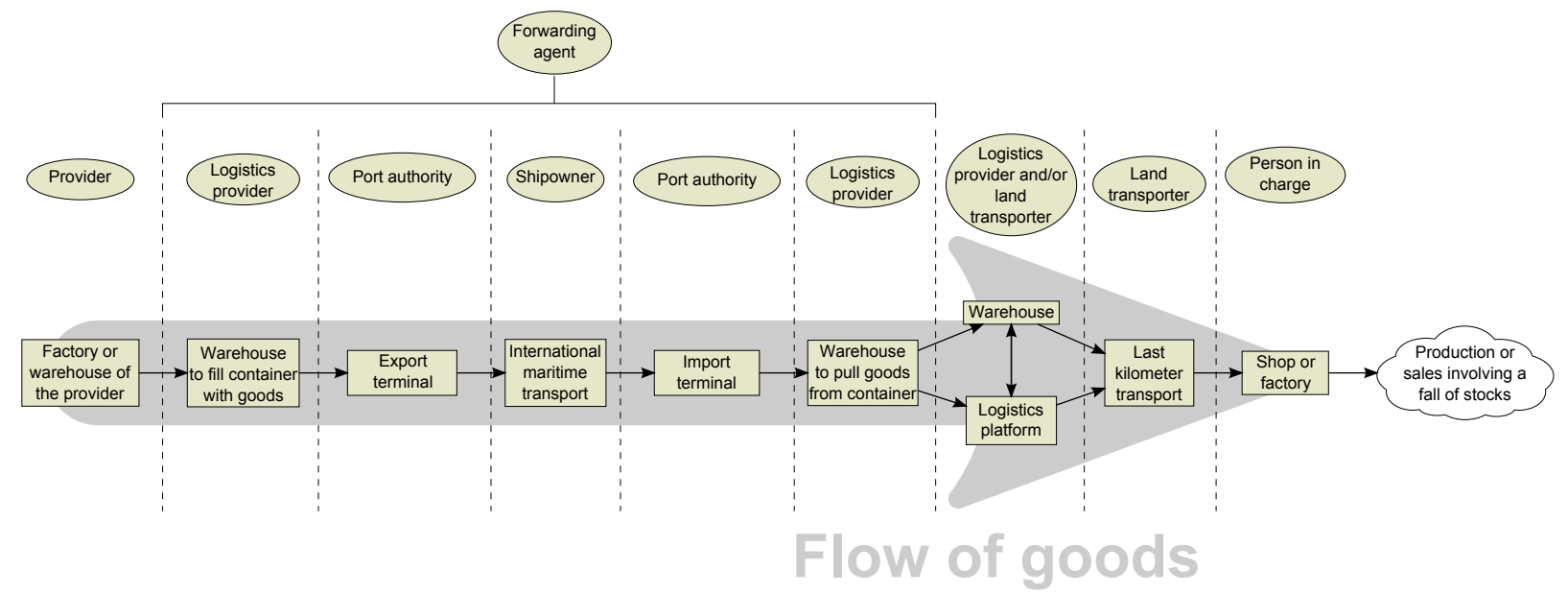

Fig. 3. Each actor manage a part of the flow

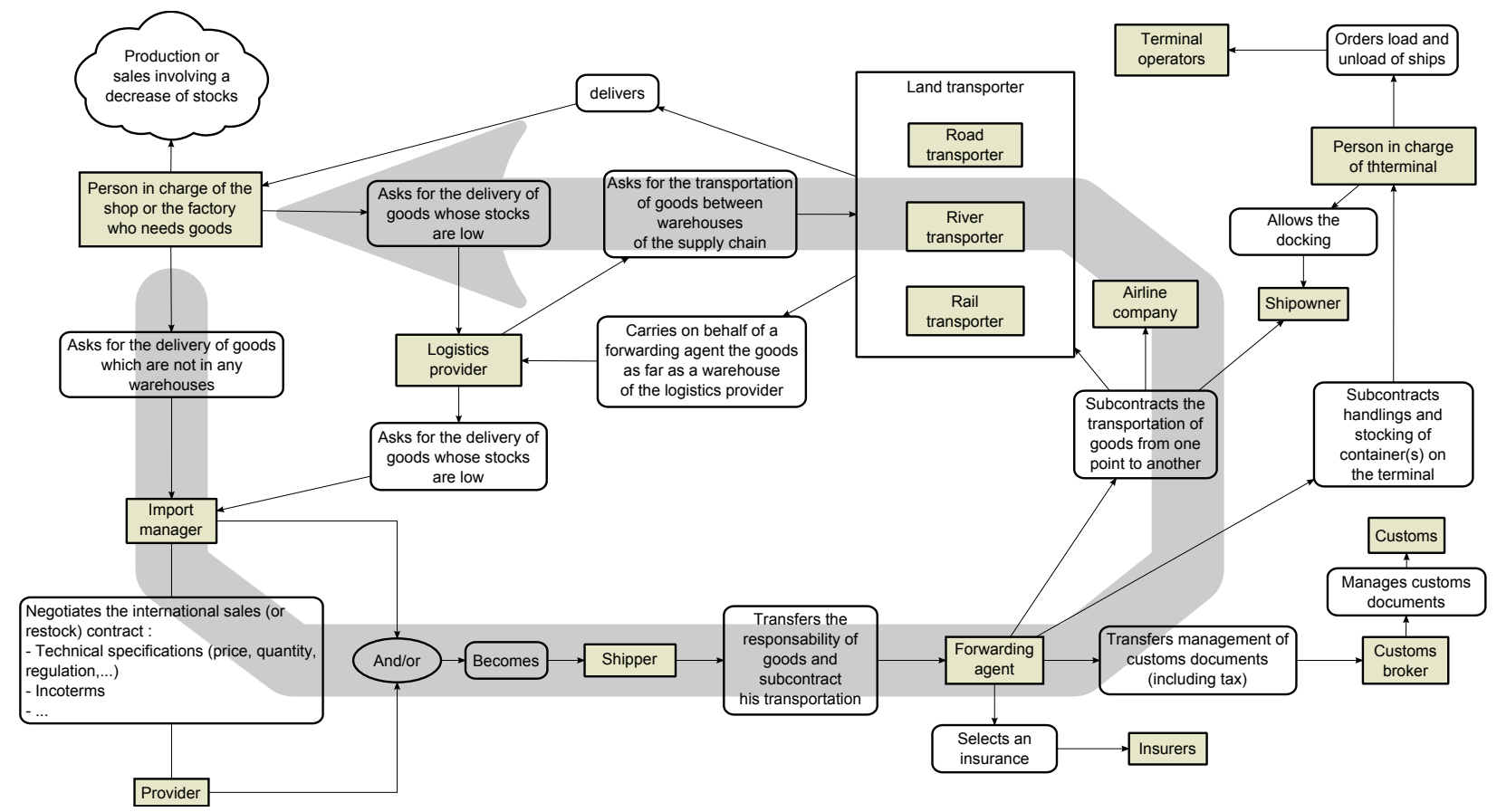

Fig. 4. Graph representation of possible interactions between agents

The forwarding agent organizes the transportation with the international transporter, the insurers and the customs. He can choose a multi-modal transportation according to the costs or work habits. The goods is delivered by the transporters into the warehouses of the supply chain which has been previously build by the logistic provider.

The network on which the goods move is represented by a dynamic graph. Its topology can be updated in real time: for instance a road can become unavailable due to an accident. And the flows on an edge increase its traffic and can lead to a slowing down of the speed, to a congestion and eventually to a traffic jam. The agents are aware of these modifications of their environment and can (or must) adapt their decisions to the dynamic of the system. There is a real retro action mechanism: the actors can have an impact on the network (they increase the traffic), and the environment can also have an impact on their decisions.

The model is also multi-scale: even if the buildings are spread over the territory and are connected to the transportation network, they also belongs to another level of network: the supply chain. The figure 5 describes it: the agents modelling a logistic provider make the decision to include some infrastructures to a supply chain according to predefined rules. The goods must follow particular path before reach their final destination: for instance, the goods within a container must be unpacked before the final delivery.

\section{RESULTS}

The model has been implemented into a simulation platform called GAMA [14]. This implementation help to check the validity of the model, but it also provides information 


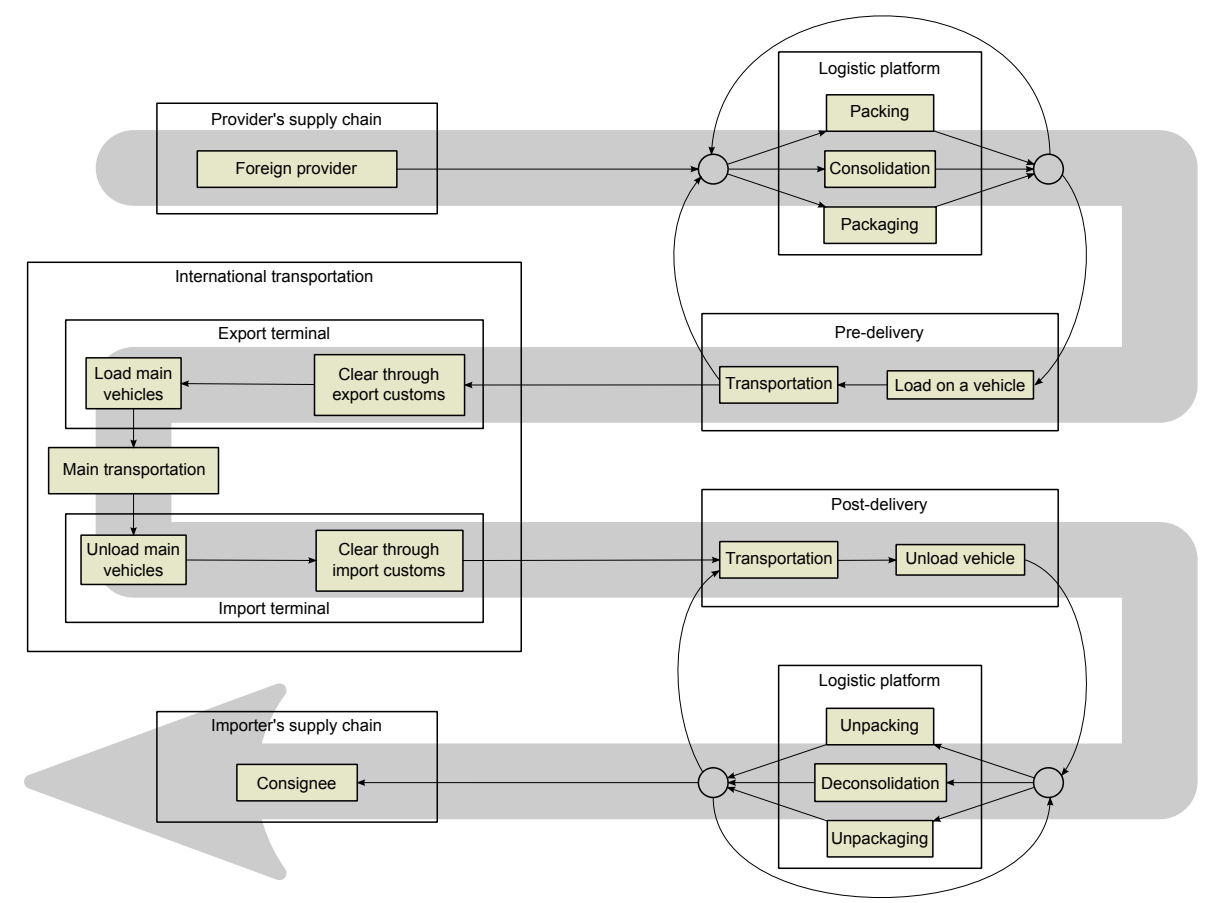

Fig. 5. Simplified representation of the different steps followed by containerized goods during the international transportation

about the system. This section highlights the overall patterns of movements of goods over the territory; describes the impacts of two behaviours of the logistic provider to manage stocks; and shows the presence of spatial clusters of warehouses and explain how it can be used to help to the decision making.

The GAMA platform is appropriate to the needs of the implementation [1], [11] because it has tools which allow to integrate geographical data. The simulation works with data on the Seine axis coming from the Devport project ${ }^{2}$. It is a logistic corridor where the road network is mostly used to transport goods. Therefore, the simulation is not multi-modal at the moment. Moreover, in order to start with simpler version of the model, the simulation keeps only as actor/agent a unique provider, some logistic provider, and some importers spread over the territory.

The importers have stocks which decrease regularly. The Huff's model [6] is used to estimate the number of customers of each importers. It allows to define a hierarchy between the importers and therefore, how much their stocks decrease. The more they have customers, the more they lose quickly their stocks. The importers must make commands to restock when the stocks are too low. Their outsourced stocks are manage by a logistic provider who must satisfy these orders by moving the goods from warehouses organised into a hierarchy inside supply chains. If the amount of goods inside the warehouses are too low, the provider send a flow of goods in order to make the restock. There is only one provider in the simulation since this work is focused on the logistic corridor, yet the providers are often outside the logistic system in another country. The movement of goods, modelled by agents, generates a traffic over the transportation network. These agents move according

\footnotetext{
${ }^{2}$ A multidisciplinary research team who works on the study of the logistic system of the Seine axis (http://www.projet-devport.fr/en/).
}

to the speed defined on the edges of the network.

On the figures 6 and 7, two simulations highlight the evolution of the traffic. The step 27 follows the initialisation process of the simulation. The step 1826 corresponds to a stabilised simulation. According to the legend, it is observed that the most used roads are, as on the reality, the ones connecting the main urban areas of the Seine axis (Paris, Rouen, Orleans and Le Havre). It matches with the overall patterns emerging at the macro level and from the local rules of the micro level that the paper describes below.

The effect of a parameter is also studied on these figures 6 and 7. A logistic provider orders the transportation of goods when the stocks are under a predefined threshold (a percentage of the stock). To measure its effect, the environment is divided into cells. Each cell is coloured according to the number of unavailable products. Just after the initialisation process, there are a lot of stock shortages spread over the territory. But after the stabilisation, at the $1826^{\text {th }}$ step, the simulation run with a threshold of $30 \%$ has less stock shortages than the other simulation. It appears that with a lower threshold, the logistic provider has less time to restock. He has not enough adaptability. However, with a higher threshold, it increases the traffic because the logistic provider make orders more often. The simulation can help to optimise this threshold in order to minimise the number of transportation and the number of unavailable products.

The next results comes from the generation of a neighbourhood graph. Each warehouse of the logistic system is modelled by a node. Two nodes are connected by an edge if the distance which separates them is less than $1 \mathrm{~km}$ (or $5 \mathrm{~km}$ for table II). The construction of such a graph leads to many connected components: two nodes belong to the same connected component if it exists a path between them. The figure 

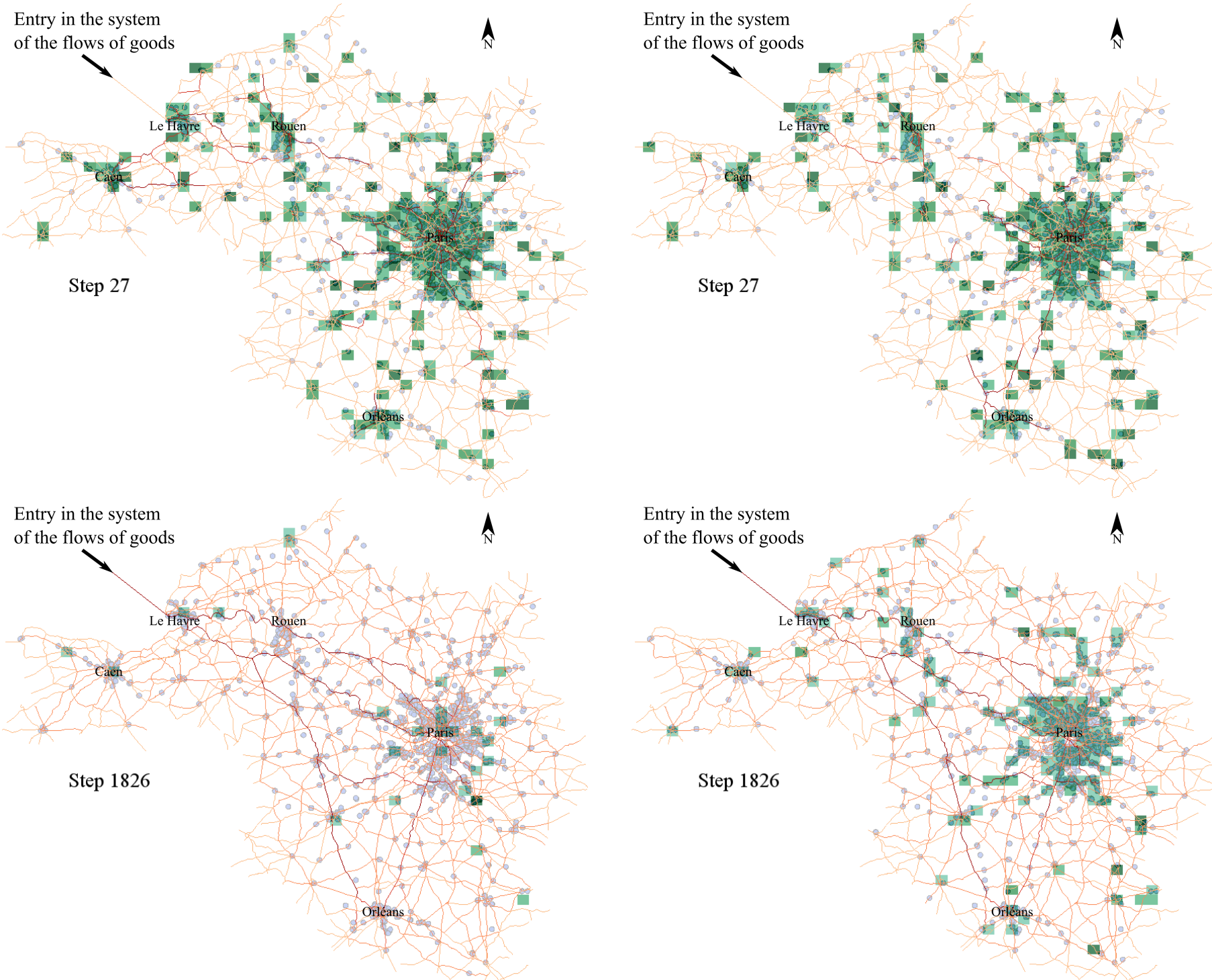

Fig. 6. Simulation $1-$ Threshold at $30 \%$ (one step $=$ one artificial hour) The more the squares are dark green, the more there are stock shortages into the region delimited by the square. The more the roads are dark red, the more there is traffic.

8 represents some of these connected components. The colour of a node corresponds to which region the warehouse belongs to. Notice that the position of each node is not representative of the real position of the warehouses, a layout algorithm places the nodes automatically in order to minimize, when it is possible, the edges crossing. The numerous connected components represents spatial clusters where warehouses are grouped together within the same area and creating empty logistic spaces within the logistic corridor. The biggest connected components listed in table I are made of warehouses of the Ile-de-France region. However, with a different configuration of the minimal distance $(5 \mathrm{~km}$ in table II), the five biggest connected components represent each main urban areas of the logistic corridor in term of warehousing activities (Paris, Rouen, Orleans, Le Havre, and Caen). The figure 9 represents the distribution of the connected components according to their size. The logarithmic scale shows that the curve describes a

Fig. 7. Simulation $2-$ Threshold at $20 \%$ (one step $=$ one artificial hour) The more the squares are dark green, the more there are stock shortages into the region delimited by the square. The more the roads are dark red, the more there is traffic.

power law. There is very few connected components with a high number of nodes, and a lot of connected components with few nodes. It means that the main part of the logistic activities is regrouped within the same, and not numerous, logistic clusters. A decision maker of spatial planning who is trying to increase the global performance of the logistic system at a low cost could be interested to maximise the accessibility of these particular areas rather than any other logistic areas.

\section{CONCLUSION}

This paper presented a way to understand how a logistic system is structured and organized. The model provides a complex system point of view and a multi-scale approach. The multi-agent system and the dynamic graphs used here allows to integrate the spatial constraints and the functional rules of such a system. In the same time, it guarantees the ability to the model to be adaptable to most of the existing logistic corridors. 


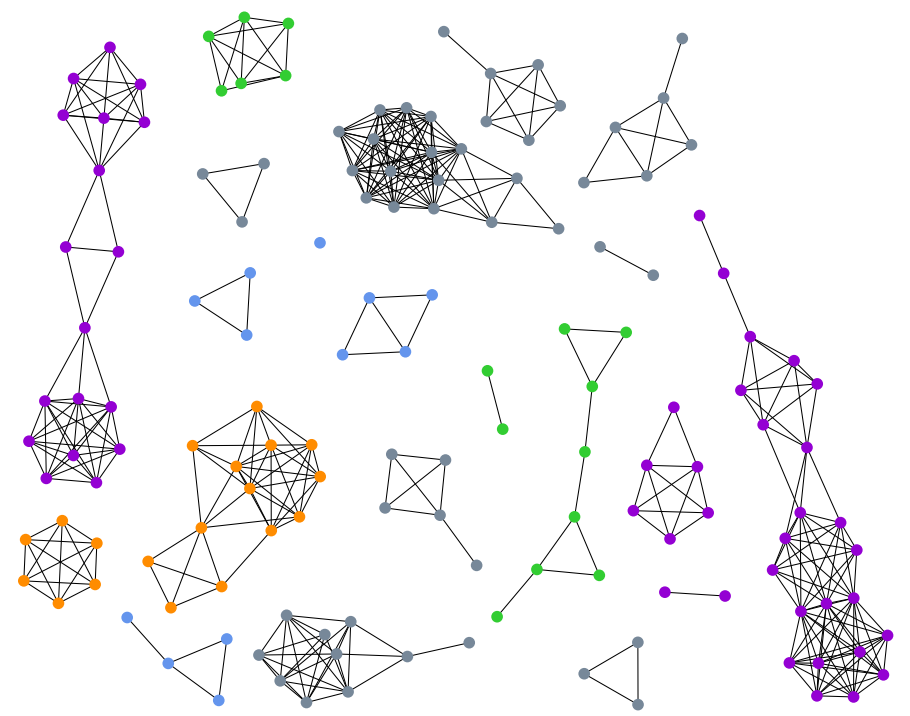

Fig. 8. Some of the connected components of the neighbourhood graph of warehouses with a maximal distance of $1 \mathrm{~km}$ - In grey: warehouses from Ilede-France; in orange: warehouses from Picardie; in green: warehouse from Centre; in violet: warehouses from Haute-Normandie; in blue: warehouses from Basse-Normandie

TABLE I. COMPOSITION OF THE FIVE BIGGEST CONNECTED COMPONENTS OF THE NEIGHBOURHOOD GRAPH WITH THE MINIMAL DISTANCE EQUAL TO $1 \mathrm{KM}$

\begin{tabular}{|l|l|}
\hline $\begin{array}{l}\text { Connected component's } \\
\text { rank }\end{array}$ & Number of warehouses \\
\hline $1^{\text {st }}$ & 226 (all from Ile-de-France) \\
\hline $2^{\text {nd }}$ & 76 (all from Ile-de-France) \\
\hline $3^{\text {rd }}$ & 71 (all from Ile-de-France) \\
\hline $4^{\text {th }}$ & 67 (all from Ile-de-France) \\
\hline $5^{\text {th }}$ & 54 (all from Ile-de-France) \\
\hline
\end{tabular}

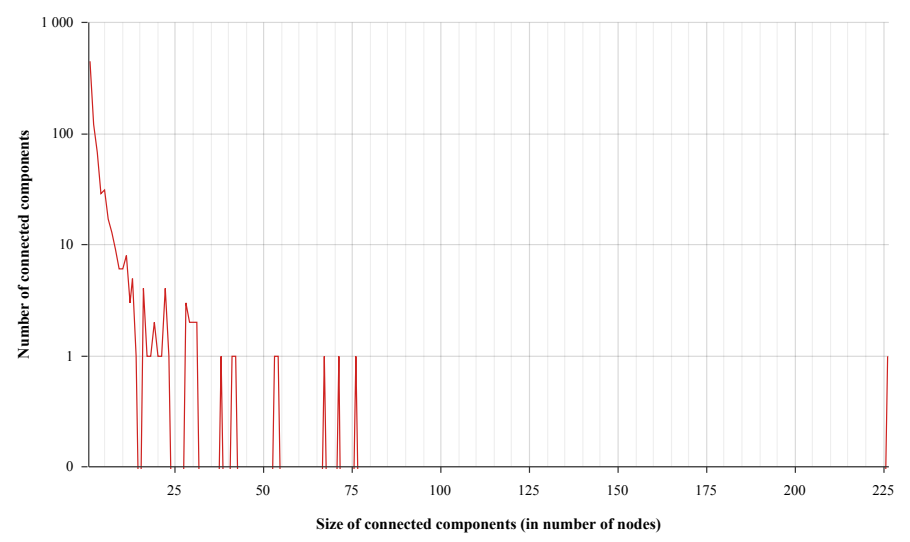

Fig. 9. The distribution of connected components according to their sizes

TABLE II. COMPOSITION OF THE FIVE BIGGEST CONNECTED COMPONENTS OF THE NEIGHBOURHOOD GRAPH WITH THE MINIMAL DISTANCE EQUAL TO 5KM

\begin{tabular}{|l|l|}
\hline $\begin{array}{l}\text { Connected component's } \\
\text { rank }\end{array}$ & Number of warehouses \\
\hline $1^{\text {st }}$ & 1834 (1826 from Ile-de-France) \\
\hline $2^{\text {nd }}$ & 118 (all from Haute-Normandie, near Rouen) \\
\hline $3^{\text {rd }}$ & 97 (all from Centre, near Orleans) \\
\hline $4^{\text {th }}$ & $76(64$ from Haute-Normandie, near Le Havre) \\
\hline $5^{\text {th }}$ & 61 (all from Basse-Normandie, near Caen) \\
\hline
\end{tabular}

The implementation on the GAMA platform provided results about the structure of the Seine axis, a logistic corridor of the Northern European range. Main roads has been highlighted, appearing as realistic data. The modification of a behaviour thanks to a parameter has shown its impact on the output of the simulation. The use of a neighbourhood graph has shown that it can be used to highlight logistic clusters. The main clusters contain the largest part of the logistic buildings of the corridor and therefore the accessibility of these areas could improve the performance of the logistic system. It illustrates that the simulation can be used to help the decision making of spatial planning.

\section{REFERENCES}

[1] R.J. Allan. Survey of agent based modelling and simulation tools. 2010.

[2] Corinna Cortes, Daryl Pregibon, Chris Volinsky, and At\&t Shannon Labs. Computational methods for dynamic graphs. Journal of Computational and Graphical Statistics, 12:950-970, 2003.

[3] Peter W. De Langen, Jan C. Fransoo, and Ben van Rooy. Business models and network design in hinterland transport. In James $\mathrm{H}$. Bookbinder, editor, Handbook of Global Logistics, volume 181 of International Series in Operations Research and Management Science, pages 367-389. Springer New York, 2013.

[4] Jacques Ferber. Multi-Agent Systems: An Introduction to Distributed Artificial Intelligence. Addison-Wesley Longman Publishing Co., Inc., Boston, MA, USA, 1st edition, 1999.

[5] A. Ferreira. On models and algorithms for dynamic communication networks: The case for evolving graphs. In $4^{e}$ rencontres francophones sur les Aspects Algorithmiques des Telecommunications (ALGOTEL'2002), Mèze, France, May 2002.

[6] David L. Huff. Defining and estimating a trading area. Journal of Marketing, 28(3):pp. 34-38, 1964.

[7] Jayanth Jayaram and Keah-Choon Tan. Supply chain integration with third-party logistics providers. International Journal of Production Economics, 125(2):262 - 271, 2010.

[8] Laurent Lévêque and Arnaud Serry. Maritime interface and metropolitan interface: questions about the logistic integration of the seine axis. In Transport Research Arena, Paris, 2014.

[9] Qiong Liu, Chaoyong Zhang, Keren Zhu, and Yunqing Rao. Novel multi-objective resource allocation and activity scheduling for fourth party logistics. Computers and Operations Research, 44(0):42 - 51, 2014.

[10] Mark Newman. Networks: An Introduction. Oxford University Press, Inc., 2010.

[11] Steven F. Railsback, Steven L. Lytinen, and Stephen K. Jackson. Agentbased simulation platforms: Review and development recommendations. SIMULATION, 82(9):609-623, January 2006.

[12] Jean-Paul Rodrigue. The geography of global supply chains: Evidence from third-party logistics. Journal of Supply Chain Management, 48(3):15-23, 2012.

[13] Guilhelm Savin. Intelligence en essaim pour la distribution de simulations dans un écosystème computationnel. $\mathrm{PhD}$ thesis, Université du Havre, January 2014.

[14] Patrick Taillandier, Duc-An Vo, Edouard Amouroux, and Alexis Drogoul. Gama: A simulation platform that integrates geographical information data, agent-based modeling and multi-scale control. In Nirmit Desai, Alan Liu, and Michael Winikoff, editors, Principles and Practice of Multi-Agent Systems, volume 7057 of Lecture Notes in Computer Science, pages 242-258. Springer Berlin Heidelberg, 2012. 